\title{
Editorial: The Developmental Seizure-Induced Hippocampal Mossy Fiber Sprouting: Target for Epilepsy Therapies?
}

\author{
Hong $\mathrm{Ni}^{1 *}$, Timo Kirschstein ${ }^{2}$, Braxton A. Norwood ${ }^{3}$ and Ching Liang Hsieh ${ }^{4}$ \\ ${ }^{1}$ Division of Brain Science, Institute of Pediatric Research, Children's Hospital of Soochow University, Suzhou, China, ${ }^{2}$ Oscar \\ Langendorff Institute of Physiology, University of Rostock, Rostock, Germany, ${ }^{3}$ Expesicor Inc., Kalispell, MT, United States, \\ ${ }^{4}$ Research Center for Chinese Medicine and Acupuncture, China Medical University, Taichung, China
}

Keywords: mossy fiber sprouting, epilepsy, hippocampus, dentate gyrus, therapies

\section{Editorial on the Research Topic}

The Developmental Seizure-Induced Hippocampal Mossy Fiber Sprouting: Target for Epilepsy Therapies?

In most patients, epilepsy arises due to various initial precipitating injuries during the developmental stages. A major challenge in the neuroscience and neuroclinical fields is understanding how this precipitating injury produces a persistent reorganization of the brain's neural network, thereby transforming the normal brain into epileptogenesis. Identifying the pathological basis of epileptic seizure may lay the foundation for the development of new antiepileptic drugs, benefiting 60 million people with epilepsy worldwide. This is why our editors chose the theme "The Developmental Seizure-Induced Hippocampal Mossy Fiber Sprouting: Target for Epilepsy Therapies?"

By using transgenic mice expressing the cell-killer gene thymidine kinase in granulosa cell progenitors or through a diphtheria toxin receptor expression strategy, newborn granule cell ablation can significantly reduce the frequency of seizures but has no effect on Mossy Fiber Sprouting (MFS) $(1,2)$. MFS develops independently of the loss of mossy fiber targets, and its presence is not necessarily associated with the development of spontaneous seizures $[(3,4)$; Cavarsan et al.]. The development of mossy fiber sprouting may be associated with epilepsy comorbidities rather than with seizure incidence. For example, people with mesial temporal lobe epilepsy (mTLE) and depression show more sprouting than those with only mTLE [(5); Godale and Danzer].

MFS is an active phenomenon, and possibly a normal adaptive mechanism that is reversible, which might be related to the replacement or restoration of lost synaptic contacts rather than to the formation of recurrent excitatory circuits in dentate granule cells [(6-8); Cavarsan et al.; Koyama and Ikegaya]. A 4-week zinc-deficient diet exacerbated MFS caused by developmental seizures, accompanied by cognitive deficits and reduced seizure thresholds. In contrast, zinc supplementation for 4 weeks significantly reduced MFS and improved the above-mentioned damage-related changes. Mitophagy-mediated zinc homeostasis via mitochondrial activation may be a potential mechanism [(9); Jin et al.; Li et al.].

This Research Topic collects seven articles: four animal studies (including one in vitro study) and three reviews. With respect to the demographics of this Research Topic collection, the corresponding authors are from Japan, the United States, Canada, Brazil, South Korea, and China. We hope that the information gathered from this topic will help promote post-epilepsy MFS study 
and help promote clinical translational medical research to better prevent and treat these injuries in the near future.

\section{AUTHOR CONTRIBUTIONS}

$\mathrm{HN}$ wrote the draft. TK, $\mathrm{BN}$, and $\mathrm{CH}$ reviewed the manuscript.

\section{REFERENCES}

1. Hosford BE, Liska JP, Danzer SC. Ablation of newly generated hippocampal granule cells has disease-modifying effects in epilepsy. J Neurosci. (2016) 36:11013-23. doi: 10.1523/JNEUROSCI.1371-16.2016

2. Hosford BE, Rowley S, Liska JP, Danzer SC. Ablation of peri-insult generated granule cells after epilepsy onset halts disease progression. Sci Rep. (2017) 7:18015. doi: 10.1038/s41598-017-18237-6

3. Ratzliff A, Santhakumar V, Howard A, Soltesz I. Mossy cells in epilepsy: rigor mortis or vigor mortis? Trends Neurosci. (2002) 25:140-4. doi: 10.1016/s0166-2236(00)02122-6

4. Nissinen J, Lukasiuk K, Pitkänen A. Is mossy fiber sprouting present at the time of the first spontaneous seizures in rat experimental temporal lobe epilepsy? Hippocampus. (2001) 11:299-310. doi: 10.1002/hipo.1044

5. Kandratavicius L, Hallak JE, Young LT, Assirati JA, Carlotti CG Jr, Leite JP. Differential aberrant sprouting in temporal lobe epilepsy with psychiatric co-morbidities. Psychiatry Res. (2012) 195:144-50. doi: 10.1016/j.psychres. 2011.06.005

6. Buckmaster P. Does mossy fiber sprouting give rise to the epileptic state? In: Scharfman H, Buckmaster P, editors. Issues in Clinical Epileptology: A View From the Bench, Advances in Experimental Medicine and Biology. Vol. 813. Dordrecht: Springer (2014).p. 161-8. doi: 10.1007/978-94-017-8914-1_13

7. Yamawaki R, Thind K, Buckmaster PS. Blockade of excitatory synaptogenesis with proximal dendrites of dentate granule cells following rapamycin treatment

\section{FUNDING}

This work was supported by the National Natural Science Foundation of China (81871024 and 81471337) and the key talent's subsidy project in science and education of Department of Public Health of Jiangsu Province (ZDRCC2016008).

in a mouse model of temporal lobe epilepsy. J Comp Neurol. (2015) 523:28197. doi: $10.1002 / \mathrm{cne} .23681$

8. Bittencourt S, Covolan L, Hamani C, Longo B, Faria F, Freymuller E, et al. Replacement of asymmetric synaptic profiles in the molecular layer of dentate gyrus following cycloheximide in the pilocarpine model in rats. Front Psychiatry. (2015) 6:157. doi: 10.3389/fpsyt.2015.00157

9. Chen N-N, Zhao D-J, Sun Y-X, Wang D-D, Ni H. Long-term effects of zinc deficiency and zinc supplementation on developmental seizure-induced brain damage and the underlying GPR39/ZnT-3 and MBP expression in the hippocampus. Front Neurosci. (2019) 13:920. doi: 10.3389/fnins.2019.00920

Conflict of Interest: BN was employed by the company Expesicor Inc.

The remaining authors declare that the research was conducted in the absence of any commercial or financial relationships that could be construed as a potential conflict of interest.

Copyright (C) $2019 \mathrm{Ni}$, Kirschstein, Norwood and Hsieh. This is an open-access article distributed under the terms of the Creative Commons Attribution License (CC BY). The use, distribution or reproduction in other forums is permitted, provided the original author(s) and the copyright owner(s) are credited and that the original publication in this journal is cited, in accordance with accepted academic practice. No use, distribution or reproduction is permitted which does not comply with these terms. 